\title{
PELATIHAN SABLON DALAM UPAYA MENINGKATKAN KETERAMPILAN SISWA/I JURUSAN MULTIMEDIA SMK MUHAMMADIYAH 2 PALEMBANG
}

\author{
Husni Mubarat1), Heri Iswandi²) \\ 1)2)Program Studi Desain Komunikasi Visual Universitas Indo Global Mandiri \\ Jl. Jenderal Sudirman, No. 629. Km 4,5Palembang Kode Pos 30128 \\ Email : husnidkv@uigm.ac.id ${ }^{11}$,wandidkv@uigm.ac.id ${ }^{21}$
}

\begin{abstract}
ABSTRAK
Sebagai salah satu bentuk komitmen Universitas Indo Global Mandiri (UIGM) Palembang dalam melaksanakan Tri Perguruan Tinggi adalah pengabdian kepada masyarakat, yang di antaranya adalah pelatihan keterampilan sablon bagi siswa/i Jurusan Multimedia SMK Muhammadiyah 2 Palembang. Pengabdian ini terlaksana dengan adanya Memorandum of Understanding (MoU) antara Program studi Desain Komunikasi Visual (DKV) UIGM Palembang dengan SMK Muhammadiyah 2 Palembang. Faktor lain yang mendorong terlaksananya pengabdian ini adalah adanya korelasi antara Jurusan multimedia dengan Program Studi DKV, yang dalam konteks ini adalah Desain Grafis. Pengabdian ini dilakukan selama tiga hari yang meliputi materi tentang pemahaman sablon, pengetahuan alat, bahan, dan teknik menyablon pada baju kaos serta memberi pengetahuan tentang cara mendesain (film sablon) dengan desain dua warna dan satu warna. Pelatihan ini dirasakan sangatlah penting bagi siswa/i SMK Muhammadiyah 2 Palembang guna menjunjang keterampilan dan kreatifitasnya di bidang Multimedia dan Desain Grafis. Di samping itu pengabdian ini juga bertujuan agar siswa/i memiliki kemampuan, spirit dan motivasi untuk bersaing baik di dunia kerja maupun membuka lapangan pekerjaan (berwiraswasta).
\end{abstract}

Kata kunci : Desain Grafis, Sablon, Multimedia

\section{PENDAHULUAN}

Maju-mundurnya suatu bangsa tidak terlepas dari pendidikan, karena melalui lembaga pendidikanlah generasi suatu bangsa dipersiapkan untuk meneruskan kehidupan bangsa untuk menjadi yang lebih baik, di antaranya adalah pembangunan ekonomi, politik, budaya, seni maupun agama. Semua itu tidak terlepas dari suatu sistem pendidikan yang membentuk Sumber Daya Manusia (SDM) yang mampu bersaing dan mandiri dalam menghadapi kemajuan zaman di era globalisasi ini, sehingga dapat menjadi generasi yang handal dan mampu membawa kemajuan bangsa. Agus Arijanto (2012: 89) mengungkapkan bahwa:

Bidang pendidikan merupakan investasi dimana pembangunan ekonomi sangat erat hubungannya dengan berkepentingan. Oleh sebab itu, bagaimanapun juga pembangunan ekonomi membutuhkan kualitas SDM yang unggul baik dalam kapasitas penguasaan Ilmu Pengetahuan dan Teknologi maupun sikap mental, sehingga dapat menjadi subjek atau pelaku pembangunan yang handal.

Peran dan fungsi perguruan tinggi sebagai implementasi dari Tri Darma memiliki kewajiban dalam membangun masyarakat untuk mendorong terciptanya transformasi sosial dan terjaganya nilai-nilai budaya bangsa. Selain dari pada itu Tri Darma perguruan tinggi juga berperan untuk memberikan dan mengembangkan Keterampilan wawasan terhadap masyarakat, baik dalam bentuk penelitian, pengajaran maupun pengabdian kepada masyarakat.Undang-Undang Nomor 20 Tahun 2003 tentang Sistem Pendidikan Nasional menyebutkan bahwa perguruan tinggi berkewajiban menyelenggarakan pendidikan, penelitian, dan pengabdian kepada masyarakat (Pasal 20 Ayat 2).

Universitas Indo Global Mandiri (UIGM) sebagai salah satu lembaga perguruan tinggi di Kota Palembang, berkomitmen melaksanakan pengabdian terhadap masyarakat secara berkala. Hal ini bertujuan untuk memberikan wawasan dan mengembangkan ketrampilan bagi masyarakat di Kota Palembang, dan Sumatera Selatan pada umumnya. Salah satu upaya tersebut adalah pelatihan 
Desain Grafis, yaitu pelatihan keterampilan sablon bagi siswa/i di SMK Muhammadiyah 2 Palembang.

SMK Muhammadiyah 2 Palembang merupakan salah satu sekolah kejuruan yang ada di kota Palembang. Salah satu jurusan di SMK tersebut adalah Jurusan Multimedia. Multimedia merupakan "alat yang dapat menciptakan presentasi yang dinamis dan interaktif yang mengkombinasikan teks, gambar, animasi, audio, dan grafik" (Suyanto, 2005: 20). Jurusan Multimedia termasuk jurusan yang baru dirintis oleh SMK Muhammadiyah 2 Palembang, yaitu didirikan pada tahun 2014. Jurusan Multimedia merupakan sebuah terobosan yang strategis, di mana tidak semua SMK di Kota Palembang yang memiliki jurusan tersebut. Walaupun terbilang baru dirintis, Jurusan Multimedia SMK Muhammadiayah 2 Palembang tersebut cukup diminati oleh pelajar di Kota Palembang.

Keberadaan Jurusan Multimedia di SMK Muhammadiyah 2 memiliki potensi untuk mempersiapkan siswanya sebagai tenaga ahli atau profesional di bidangnya, yang dapat bersaing di dunia pekerjaan ataupun siap untuk membuka lapanagan pekerjaan, baik untuk dirinya sendiri maupun untuk orang lain.Saat ini, jurusan multimedia mengalami kemajuan yang sangat pesat, sebagai tolak ukurnya adalah berkembangan media televisi, baik skala nasional maupun skala lokal. Kemajuan media televisi ini tentunya memberi peluang dunia kerja bagi lulusan jurusan multimedia. Terbukanya peluang kerja di bidang multimedia tentunya tidak terlepas dari persaingan.

Jurusan multimedia tidak terlepas dari elemen grafis, sehingga di bidang Ilmu Desain Komunikasi Visual terdapat mata kuliah multimedia, yang merupakan mata kuliah wajib. Grafis dan multimedia adalah dua bidang ilmu yang saling terkait dan saling mendukung satu sama lainnya. Untuk itu perlu adanya upaya untuk meningkatkan keterampilan siswa Jurusan Multimedia SMK Muhammadiyah 2 Plaembang di bidang grafis, salah satunya adalah keterampilan sablon kaos.Cetak sablon merupakan bagian dari ilmu grafika terapan yang bersifat praktis. Jika diuaraikan secara verbal cetak sablon dapat diartikan sebagai kegiatan cetak-mencetak grafis dengan menggunakan kain gasa, biasa disebut dengan screen, pada bidang yang menjadi sasaran cetak. Gambar yang tercetak pada objek cetak akan sesuai dengan model atau klise yang terdapat pada screen (Guntur Nusantara, 2003: 4).

Selama kegiatan pelatihan, siswa/iJurusan Multimedia SMK Muhammadiyah 2 cukup antusias mengikuti pelatihan tersebut, karena keterampilan sablon kaos merupakan suatu pengetahuan dan keterampilan yang belum pernah didapatkan oleh siswa tersebut. Sebagaimana dialog dan diskusi yang penulis lakukan dengan beberapa guru Jurusan Multimedia, salah satunya adalah Pak Herman, beliau mengungkapkan bahwa Jurusan Multimedia SMK Muhammadiyah 2 ini memang diakui masih kekurangan guru, khususnya di bidang grafis. Hal ini juga dapat dimaklumi karena jurusan ini baru dirintis. Harapan kedepannya jurusan Multimedia SMK Muhammadiyah 2 memiliki guru di bidang grafis. Dengan adanya pelatihan keterampilan sablon kaos ini, diharapkan siswa terpacu untuk mengembangkan keterampilan tersebut sehingga nantinya dapat membekali diri siswa untuk berwirausaha.

\subsection{Tujuan}

1. Memberikan pengetahuan dan pemahaman kepada SMK Muhammadiyah 2 Palembang tentang proses menyablon, khususnya pada media baju kaos.

2. Memberi pengetahuan kepada peserta tentang jenis-jenis bahan dan alat sablon.

3. Melatih keterampilan dan kreativitas serta memberi doronganterhadap siswa/i agar termotivasi untuk membuka usaha sablon.

4. Melatih keterampilan dan kreatifitas siswa/i SMK Muhammadiyah 2 Palembang di bidang desain grafis agar mampu memadukannya dengan keterampilan sablon.

\subsection{Manfaat}

1) Dapat memberi wawasan dan pengetahuan bagi guru dan siswa/i SMK Muhammadiyah 2 Palembang tentang dasar-dasar proses menyablon.

2) Dapat memberi wawasan pengetahuan terhadap siswa/i tentang bahan dan alat sablon. 
3) Dapat memberi peluang usaha bagi siswa SMK Muhammadiyah 2 Palembang, khususnya di bidang sablon kaos.

4) Dapat meningkatkan keterampilan dan kreatifitas siswa/i SMK Muhammadiyah 2 Palaembang di bidang desain grafis.

\section{METODE PELAKSANAAN}

Metode dapat diartikan sebagai sebuah cara atau strategi atau jalan yang harus dilalui untuk mencapai suatu tujuan. Dalam kamus bahasa Indonesia dijelaskan bahwa metode adalah "cara yang telah teratur dan terpikir baik-baik untuk mencapai suatu maksud" (WJS Poerwadarminta, 1976: 648). Dalam pelaksanaan pengabdian Pelatihan sablon di SMK Muhammadiyah 2 Palembang terdiri dari beberapa metode yang diterapkan, di antaranya adalah:

1) Menyusun Materi

Sebelum pelaksanaan pelatihan sablon dilaksanakan, materi pelatihan terlebih dahulu disusun sesuai dengan tema pelatihan yang akan dilaksanakan, yaitu materi tentang pengenalan sablon, alat dan bahan yang dibutuhkan serta materi desain, yaitu cara membuat desain dan film cetak sablon dengan program Corell Draw.

2) Pembagian Kelompok

Kelompok dibagi menjadi dua kelompok sesuai dengan kelas Multimedia, yaitu kelas VIII dan kelas IX, setiap kelas berjumlah 30 peserta. Pembagian kelas ini melakukan koordinasi dengan guru kelas sebagai guru pembimbing siswa. Metode ini bertujuan agar pelatihan sablon dapat berjalan secara efektif dan kondusif mengingat jumlah peserta yang cukup banyak.

3) Menyampaikan Materi

Masing-masing kelompok secara bergantian untuk mendapatkan materi, kelompok kelas VIII dihari pertama diberi materi (bekal) tentang cara membuat desain dan film sablon kaos dengan program Corell Draw, sedangkan untuk kelas IX diberi materi tentang pengetahuan sablon, bahan dan alat-alat yang diperlukan.

4) Pelaksanaan Praktek Sablon Kaos

Pelaksanaan praktek sablon menggunakan metode demonstrasi, yaitu penyajian materi dengan cara memperagakan di depan peserta atau siswa/i SMK Muhammadiyah 2 Palembang secara langsung mengenai tahapan-tahapan yang dilakukan dalam proses menyablon (sablon kaos). Metode ini juga memperagakan teknik menyablon dengan satu warna dan dua warna, dengan metode ini siswa/i tersebut dapat mengetahui dan mempraktekkan menyablon kaos secara langsung.

5) Metode Bimbingan

Metode ini dilakukan ketika siswa/i memulai melaksanakan praktek menyablon. Metode bimbingan ini dilakukan perindividu terhadap siswa/i yang bertujuan agar siswa/i tersebut dapat mengatasi permasalahan dalam proses menyablon, khususnya masalah teknik, seperti cara memegang racel, cara menuangkan tinta sablon, jumlah tinta sablon yang dibutuhkan untuk satu warna, dan lain sebagainya.

\section{HASIL DAN PEMBAHSAN}

\subsection{Desain Sablon baju Kaos}

Secara garis besar konsep desain sablon baju kaos SMK Muhammadiya 2 Palembang yaitu kombinasialat kamera dengan tulisan SMK Muhammadiyah 2 Palembang sebagai headlinenya. Desain dibuat dengan minimalis (sederhana), hal ini bertujuan agar siswa/i mudah memahami bagaimana membuat desain yang dijadikan film cetak sablon. Hampir secara keseluruhan desain film cetak sablon baju kaos untuk satu warna, namun desain tersebut dapat pula diolah menjadi desain film sablon dua warna. 
Berikut adalah beberapa desain yang dihasilkan:

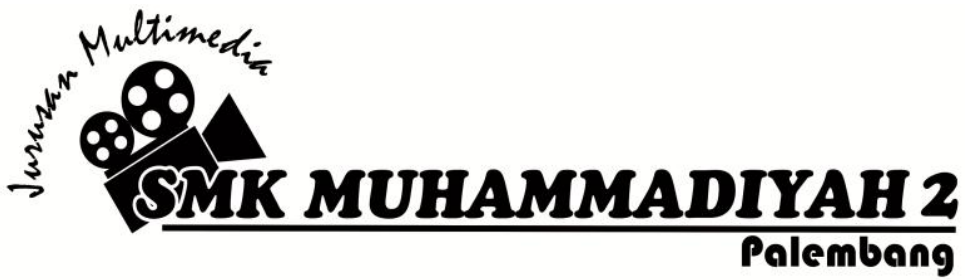

Gambar 1. Desain sablon kaos dengan program Corell Draw Ukuran: 18 x 5 CM | Jenis font: Mistral, Cooper Black, Bauhaus 93

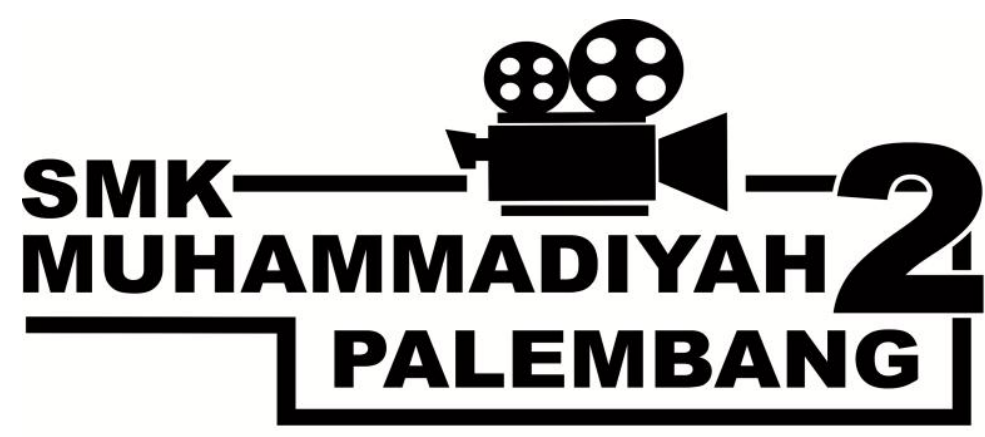

Jurusan Multimedia

Gambar 2. Desain Sablon Kaos dengan program Corell Draw Ukuran: 22 x 10 CM | Jenis Font: Arial Black

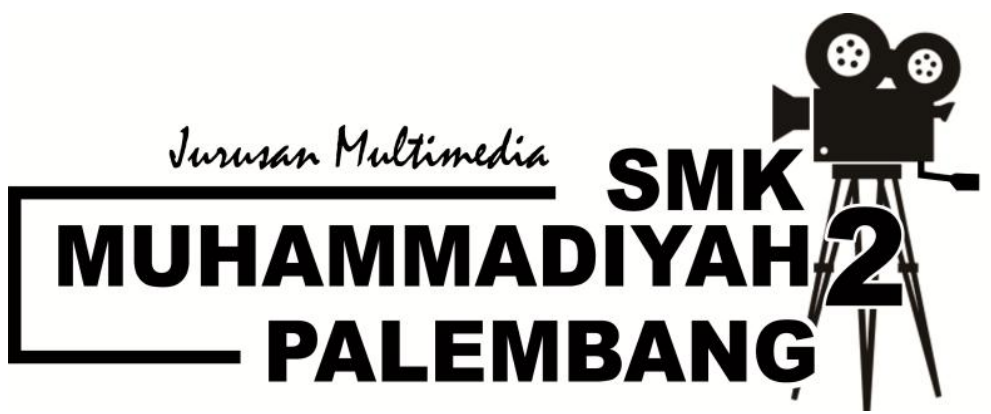

Gambar 3. Desain Sablon Kaos dengan program Corell Draw Ukuran: 20 × 8 CM | Jenis Font: Arial Black

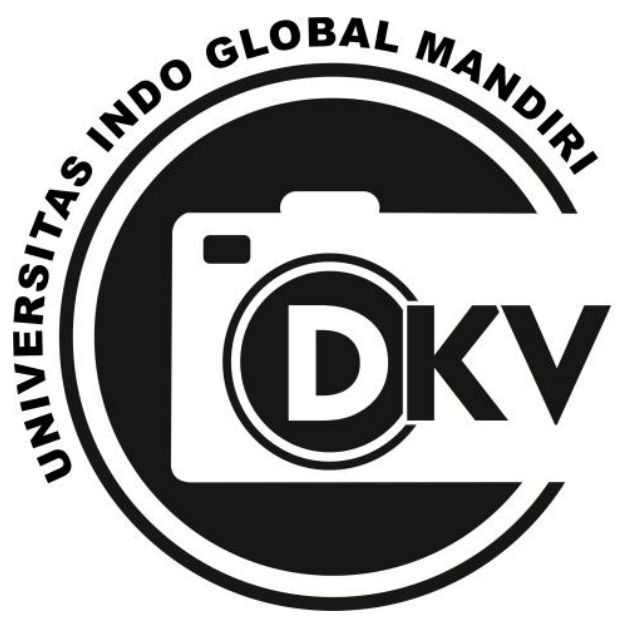

Gambar 4. Desain Sablon Kaos dengan program Corell Draw Ukuran: 16 x 10 CM | Jenis Font: Stencil, Arial Black 


\subsection{Alat-Alat Sablon}

Tabel 1. Jenis-jenis dan fungsi alat sablon

\begin{tabular}{|c|c|c|}
\hline NO & NAMA ALAT SABLON & KETERANGAN \\
\hline 1 & 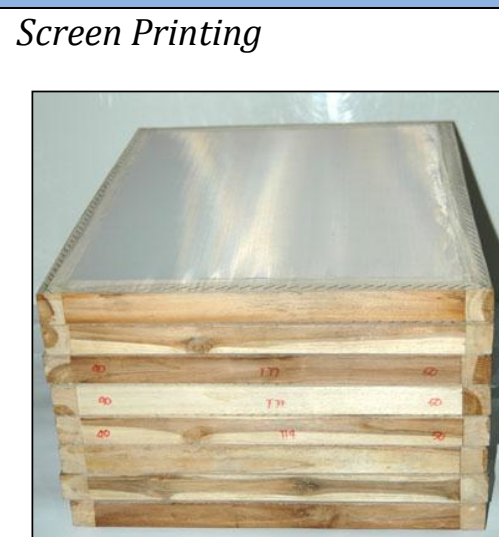 & $\begin{array}{l}\text { Screen Printing adalah sebuah media yang berguna } \\
\text { sebagai mengantarkan tinta sablon ke obyek sablon. } \\
\text { Biasanya yang digunakan adalah Bentuknya balok } \\
\text { persegi empat kemudian dipasang kain khusus. } \\
\text { screen biasanya berukuran } 30 \times 40 \mathrm{~cm}, 20 \times 30 \mathrm{~cm} \text {, } \\
\text { bahkan ada screen ukuran "jumbo" yang biasa } \\
\text { dipakai ketika kita membuat spanduk. pada screen } \\
\text { ada jenis lubang di sablonnya Misalnya Screen yang } \\
\text { digunakan yaitu jenis T48, T54, T61,T77, T90 dan } \\
\text { seterusnya. harga Screen Sablon ini kisaran 30rb- } \\
\text { 50rb tergantung daerah. }\end{array}$ \\
\hline 2 & Rakel & $\begin{array}{l}\text { Rakel berfungsi untuk menarik dan menekan tinta } \\
\text { sablon dari screen yang akan dicetak. Rakel memiliki } \\
\text { berbagai jenis, sesuai dengan kebutuhannya untuk } \\
\text { menyablon, seperti sablon basis air, sablon basis } \\
\text { minyak. Masing-masing menyesuaikan dengan jenis } \\
\text { karet rakel. Jenis karel yang lunak biasanya } \\
\text { digunakan untuk sablon baju kaos sedangkan jenis } \\
\text { karet rakel yang keras biasanya digunakan untuk } \\
\text { menyablon stiker, akrelik, kaca dan lain sebagainya. }\end{array}$ \\
\hline 3 & Meja Af & $\begin{array}{l}\text { Meja afdruk adalah sebuah meja yang memiliki } \\
\text { peranuntuk melakukan afdruk film sablon. meja ini } \\
\text { seperti meja pada umumnya, namun terdapat sebuah } \\
\text { lampu neon, atau bohlam sebagai sumber cahaya } \\
\text { untuk kita melakukan penyinaran film sablon. proses } \\
\text { inilah yang merupakan proses afdruk atau expossure } \\
\text { sob. meja sablon ini kita sesuaikan ukurannya } \\
\text { dengan ukuran screen sablon yang akan kita } \\
\text { gunakan. }\end{array}$ \\
\hline 4 & Hair Drayer & $\begin{array}{l}\text { Alat ini berfungsi untuk mempercepat pengeringan } \\
\text { afdruk atau emulsi. Alat ini juga berfungsi untuk } \\
\text { mempercepat pengeringan screen yang sudah } \\
\text { dijadikan film. }\end{array}$ \\
\hline
\end{tabular}




\begin{tabular}{|l|l|l|}
\hline 5 & Hair Spayer & \\
\hline 6 & Lakban Bening & \\
diafdruk pada screenprinting.
\end{tabular}

\subsection{Bahan-Bahan Sablon}

Tabel 2. Jenis-jenis Bahan sablon

\begin{tabular}{|c|l|l|}
\hline NO & \multicolumn{1}{|c|}{ NAMA BAHAN SABLON } & \multicolumn{1}{c|}{ KETERANGAN } \\
\hline 1 & Bahan Emulsi & $\begin{array}{l}\text { Bremol adalah bahan emulsi yang digunakan dalam } \\
\text { proses pencetakan, yaitu proses pemindahan dari } \\
\text { film negatif ke positif melalui cahaya lampu atau } \\
\text { matahari. }\end{array}$ \\
\hline 2 & Jenis Tinta Sablon Kaos & \\
\hline
\end{tabular}




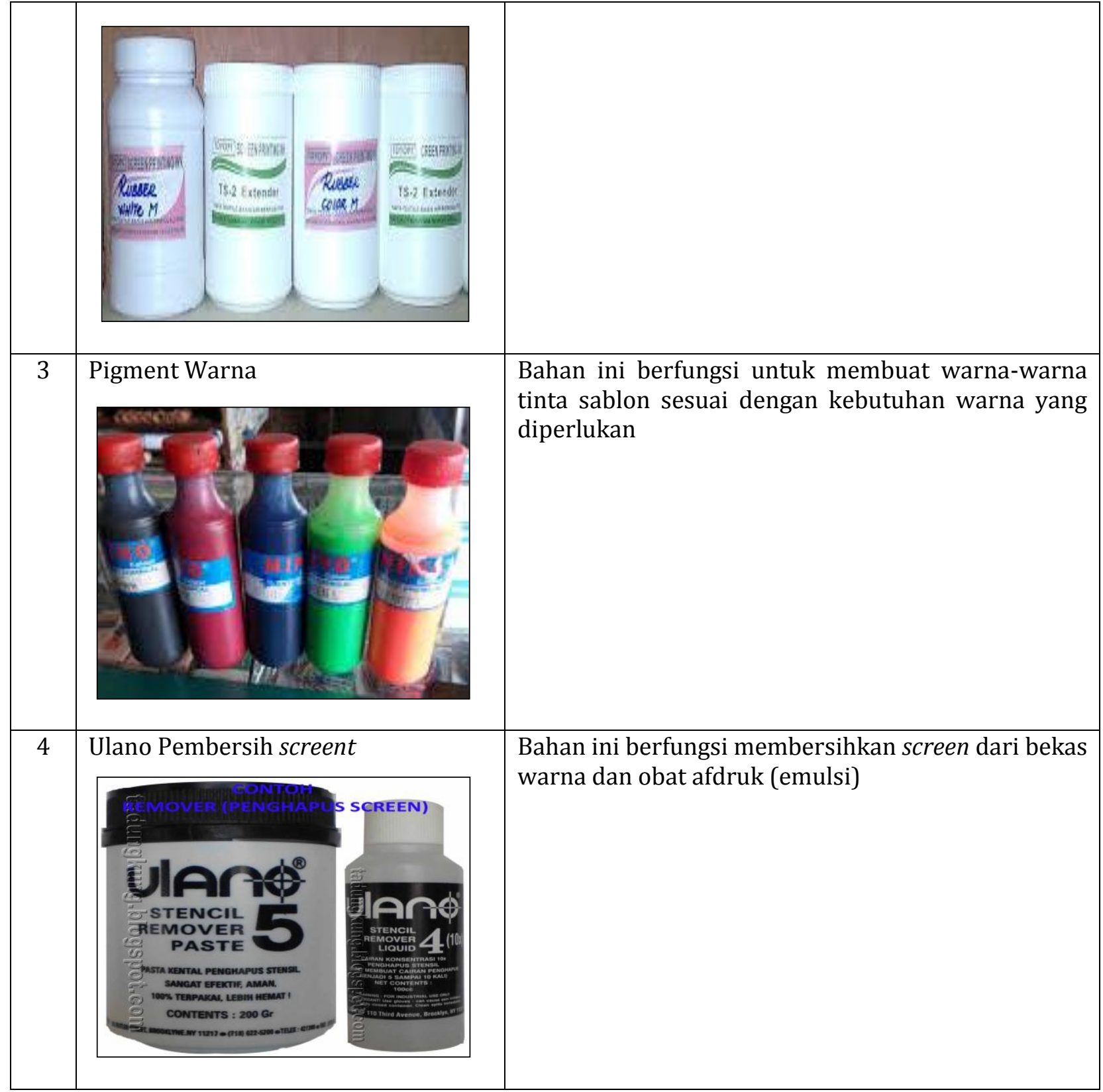

\subsection{Proses dan Hasil Sablon Baju Kaos}

Tabel 3. Proses dan Hasil Sablon

\begin{tabular}{|c|c|c|}
\hline NO & TAHAPAN-TAHAPAN SABLON & URAIAN \\
\hline 1 & &
\end{tabular}




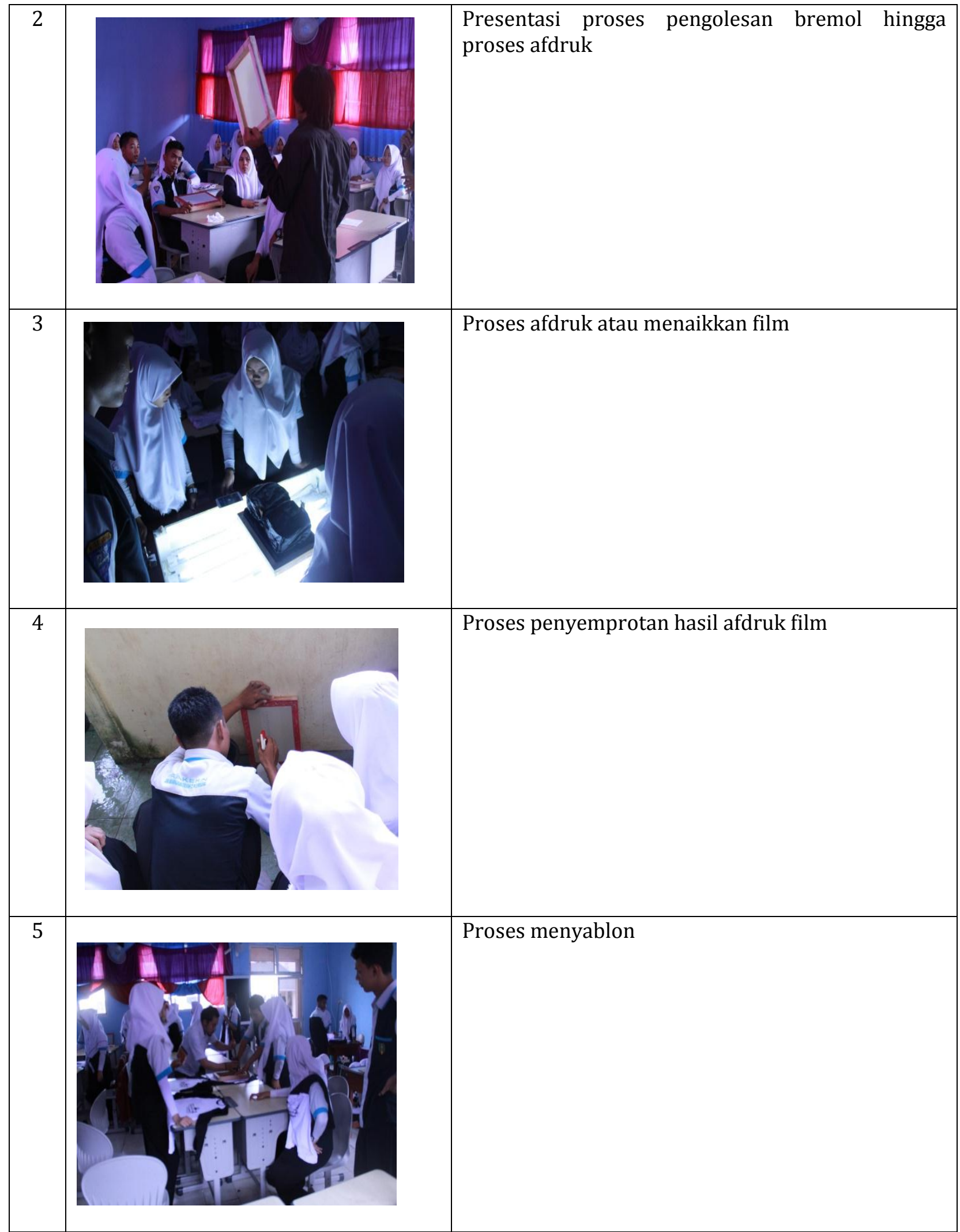




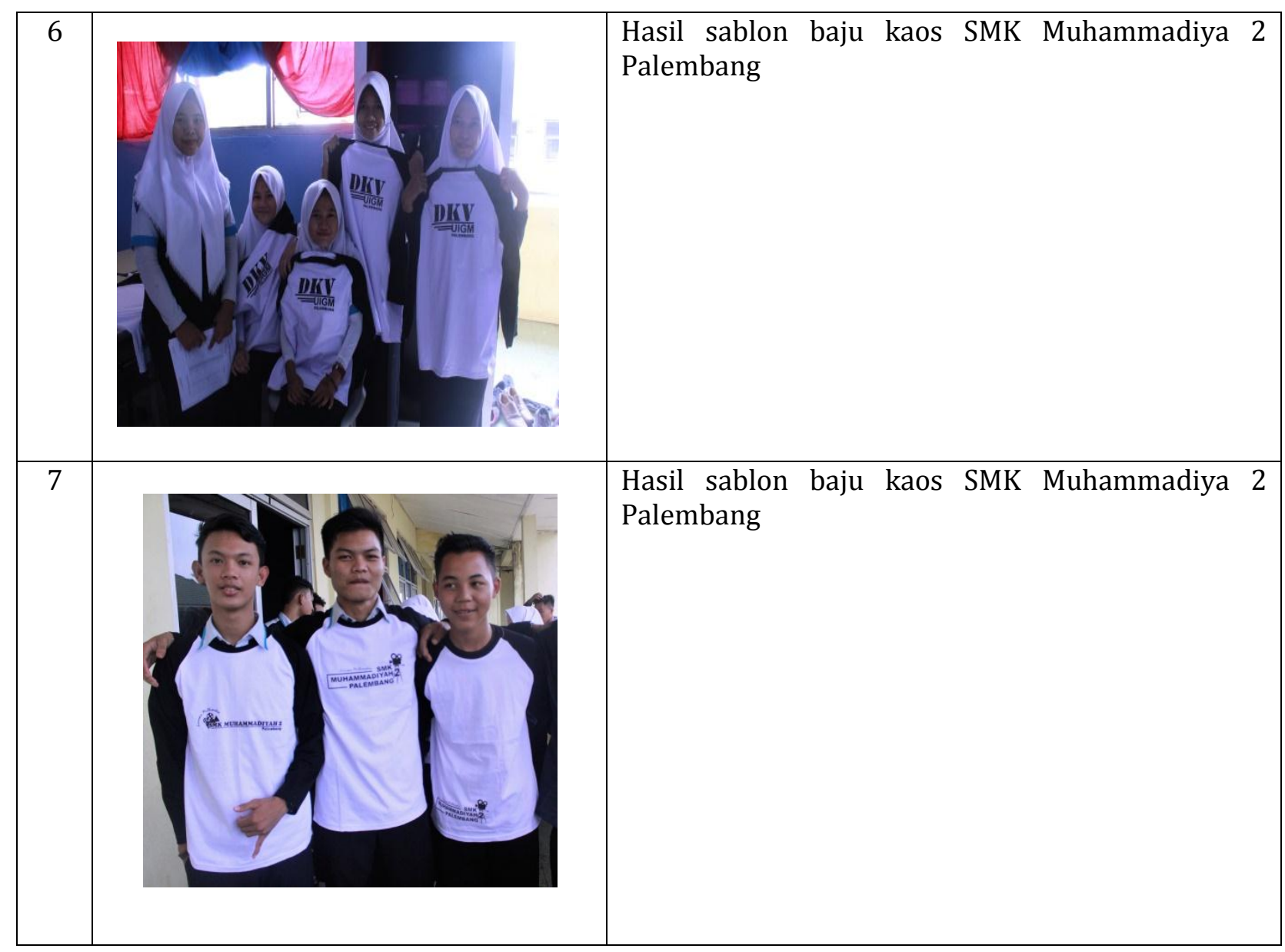

\section{KESIMPULAN}

Melaksanakan Tridarma Perguruan Tinggi adalah kewajiban yang harus diselenggarakan oleh setiap Perguruan tinggi baik Negeri maupun Swasta, sebagaimana yang tercantum dalam UU No. 20 Tahun 2003.Dalam rangka memenuhi kewajiban tersebut, maka diselenggarakannya Pengabdian Masyarakat oleh Prodi Desain Komunikasi Visual UIGM di SMK Muhammadiyah 2 Palembang yang dalam hal ini adalah Jurusan Multimedia. Adapun bentuk pelaksanaan pengabdian tersebut adalah berupa pelatihan Sablon baju kaos.

Pelatihan ini diselengarakan selama tiga hari dengan jumlah peserta lebih kurang sekitar 65 orang siswa yang terdiri dua kelompok. Selama proses pelatihan berjalan, siswa/i sangat antusias mengikuti tahapan demi tahapan yang dilaksanakan selama proses pelatihan tersebut. Indikasi ini dapat dilihat sebagai fakta besarnya minat siswa/i terhadap desain grafis. Kegiatan pelatihan ini memberikan pengetahuan dan pengalaman baru bagi siswa/i tersebut, seperti mengetahui alat, bahan dan proses menyablon. Di samping siswa/i mendapatkan ilmu mengenai sablon, dan meningkatkan kemampuan untuk membuat desain sablon, siswa/i juga dapat memahami peluang usaha di bidang sablon.

Untuk lebih meningkatkan pengetahuan dan pemahaman siswa/i SMK Muhammadiyah 2 khususnya Jurusan Multimedia, kegiatan ini perlu dilaksanakan secara berkala. Hal ini tentunya tidak terlepas dari faktor keterkaitan Desain Grafis dengan Multimedia. Dengan demikian siswa/i dapat meningkatkan kreatifitas dan keterampilannya di bidang ilmu tersebut.

\section{UCAPAN TERIMA KASIH}

Ucapan terima kasih disampaikan kepada:

1. Dr. H. Marzukie Alie, selaku Rektor Universitas IGM Palembang, yang telah memberi izin dan dukungan terhadap kegiatan ini, sehingganya kegiatan pengabdian ini dapat berjalan sesuai dengan yang dijadwalkan. 
2. Dr. Sumi Amariena Hamim ST., MT, selaku Wakil Rektor I, yang telahmemberi dukungan terhadap kegiatan pengabdian masyarakat ini.

3. John Roni Coyanda, S.Kom., M.Si, Wakil Rektor II, yang telah memberi dukungan terhadap pelaksanaan kegiatan ini.

4. Terttia Avini, S.Kom., M.kom, selaku Ketua Lembaga Penelitian dan Pengabdian Masyarakat (LP2MK) Universitas Indo Global Mandiri.

5. Yosef Yulius, S.Sn., M.Sn, selaku Ketua Program Studi Desain Komunikasi Visual (DKV) yang telah mengkoordinir dosen-dosen dan mahasiswa DKV dalam pelaksanaan kegiatan ini, sehingga pengabdian masyarakat ini berjalan sesuai dengan yang diharapkan.

6. Dosen dan mahasiswa DKV yang telah bekerjasama untuk menyukseskan kegiatan pengabdian masyarakat ini.

7. Ucapan terima kasih juga disampaikan kepada Yulia Andriani, SE, selaku Kepala sekolah SMK Muhammadiyah 2 Palembang yang telah bersedia bekerjasama dalam pelatihan keterampilan sablon.

8. Bapak dan Ibu Guru SMK Muhammadiyah 2 Palembang, khususnya Jurusan multimedia yang telah memberi dukungan dan kerjasama yang baik sehingga kegiatan pengabdian ini dapat terlaksana sesuai dengan harapan.

\section{DAFTAR PUSTAKA}

Arijanto, Agus. 2012. Etika Bisnis. Jakarta: Rajawali Pers.

Nusantara, Guntur. 2003. Panduan Praktis Cetak sablon: Memanfaatkan Waktu luang. Tanggerang: Penerbit PT Kawan Pustaka.

Poerwadarminta, WJS. 1976. Kamus Besar Bahasa Indonesia. Jakarta: Bali Pustaka.

Suyanto, M. 2005. Multi Media Alat Untuk Meningkatkan Keunggulan Bersaing. Andi, Yogyakarta. https://www.google.co.id- sablonnusantara.blogspot.com.

www.rumahsabloncepat.com/teknik-sablon-manual-dari-awal-hingga-akhir. 